A $\mathrm{Cublications}$ Rec. Nat. Prod. 13:5 (2019) 405-412

\title{
Volatile Oil Constituents of Crataegus azarolus L. and
}

\section{Crataegus pallasii Grisb.}

\author{
Najat Agiel $\odot^{* 1,2}$, Duygu Yiğit Hanoğlu $\odot^{3}$, Azmi Hanoğlu $\odot^{1}$, \\ Kemal H. C. Başer $\odot^{1}$ and Filiz Mericli $\odot^{1,4}$ \\ ${ }^{1}$ Near East University, Faculty of Pharmacy, Department of Pharmacognosy, Nicosia-Turkish \\ Republic of Northern Cyprus \\ ${ }^{2}$ The University of Tripoli, Faculty of Education, Department of Biology, Libya \\ ${ }^{3}$ Near East University, Faculty of Pharmacy, Department of Pharmaceutical Botany, Nicosia- \\ Turkish Republic of Northern Cyprus \\ ${ }^{4}$ Near East University, Faculty of Pharmacy, Department of Phytotherapy, Nicosia - Turkish \\ Republic of Northern Cyprus
}

(Received November 30, 2018; Revised February 05, 2019; Accepted February 10, 2019)

\begin{abstract}
In this study the volatile oils constituents of the inflorescence and unripe fruits of Crataegus azarolus L. and Crataegus pallasii Grisb. were investigated. Fifty-four compounds were identified by GC and GC-MS analysis. The major outstanding constituents of the essential oil in all samples (dried and fresh C. azarolus and dried C. pallasii) were; tricosane $(33.8 \%, 29.3 \%, 34.0 \%)$, pentacosane $(24.6 \%, 21.1 \%, 30.8 \%)$, heptacosane $(12.5 \%, 10.2 \%, 11.7 \%)$, and tetracosane $(6.0 \%, 5.6 \%, 5.7 \%)$, respectively. Besides these alkanes, ten compounds (nonanal, $\beta$-elemene, undecanal, $\beta$-caryophyllene, $(E, E)$ - $\alpha$-farnesene, eicosane, hexyl benzoate, $(Z)$-3-hexenyl benzoate, $(E)$-2-hexenyl benzoate, docasane) were determined in all samples. Carvacrol, carvacryl acetate, carvone, and thymol were determined for the first time from $C$. pallasii essential oil. $(E)-\beta$-damascenone was determined only in dried $C$. azarolus oil; sesquiterpene compounds valencene, $\alpha$-selinene and $\beta$-selinene, $\delta$ cadinene, germacrene $\mathrm{D}$, selina-3,7(11)-diene, spathulenol, and $\delta$-cadinol were determined only in fresh $C$. azarolus sample. On the other hand $(2 E, 6 E)$-farnesol was determined in dried C. azarolus and C. pallasii samples.
\end{abstract}

Keywords: Crataegus azarolus; Crataegus pallasii; volatile constituents; GC-MS analysis. () 2019 ACG Publications. All rights reserved.

\section{Introduction}

Crataegus species (Rosaceae), more commonly known as "Alıç", "Yemişen" or "Mosphilla" in Cyprus and as "Zaarour" in the Middle Eastern Countries, is a diverse genus of flowering, fruit bearing shrubs or small trees that grow mostly in temperate zones, including countries of North Africa, Europe and Mediterranean basin, Western Asia, India, China and North America [1,2]. Crataegus species (Hawthorn) have been used traditionally since ancient times and the first report ofpatients treated with $C$. oxyacantha that were suffering from various heart illnesses was in 1896 [3].

Researches documented that bioflavonoid-like complexes appeared to be primarily responsiblefor the cardiac actions of the plant which included oligomeric procyanidins (OPC) and

*Corresponding author: E-Mail: najataghil@yahoo.com; Phone: 090-533-8562632 
flavonoids, hyperoside, quercetin, and vitexin. The action of these compounds on the cardiovascular system hasled to the development of drugs from leaf and flower extracts, which are widely used in Europe $[1,4]$.

Recent reports showed that numerous diverse chemical constituents were in the leaves, fruits, and flowers of Crataegus which include sugars and sugar alcohols, organic and phenolic acids, terpenes, essential oils (including mixtures of terpenoids and phenylpropanoids) [5]. While intensive work has been done on the major bioactive compounds in the chemical profile of Crataegus species little attention has been given to volatile constituents [6]. This could be due to the low concentrations of these metabolites but they could contribute to the synergic effect of the plant and explain some therapeutic effects such as sedative effect [4]. Therefore, we aimed to study the volatile constituents of the flowers and fruits of two Crataegus species. C. azarolus growing in Cyprus and C. pallasii growing in Libya.

\section{Materials and Methods}

\subsection{Plant Material}

Crataegus azarolus samples were collected from two regions in Northern Cyprus; Cengizköy / Lefke on March 1, 2018, and from Near East University Campus in Nicosia on March 26, 2018. Samples were deposited at the Herbarium of the Near East University with voucher numbers NEUN 6899 and NEUN 6900, respectively. Crataegus pallasii samples were collected from El-merj in Libya from Bata Region on March 23, 2018. Samples were authenticated by Dr. Mohammed Nuri Abuhadra and deposited in the Herbarium of the Faculty of Science, Botany Department, the University of Tripoli in Libya with voucher number: D6831131.

\subsection{Isolation of Essential Oil}

For the isolation of the essential oils, fresh and dry inflorescences and unripe fruits were separated from branches of C. azarolus and C. pallasii. $150 \mathrm{~g}$ of each fresh and dry C. azarolus and 85 $\mathrm{g}$ of dry C. pallasii inflorescences and unripe fruits were hydrodistilled in a Clevenger-type apparatus for $3 \mathrm{~h}$. The resulting oils were trapped with hexane and stored at $4^{\circ} \mathrm{C}$ until used.

\subsection{Gas Chromatography (GC) and Gas Chromatography-Mass Spectrometry (GC-MS) Analysis}

\subsubsection{GC-MS Analysis}

The GC-MS analysis was carried out with an Agilent 5977B GC-MSD system. Innowax FSC column ( $60 \mathrm{~m} \times 0.25 \mathrm{~mm}, 0.25 \mu \mathrm{m}$ film thickness) was used with helium as carrier gas $(0.8 \mathrm{~mL} / \mathrm{min})$. GC oven temperature was kept at $60^{\circ} \mathrm{C}$ for $10 \mathrm{~min}$ and programmed to $220^{\circ} \mathrm{C}$ at a rate of $4^{\circ} \mathrm{C} / \mathrm{min}$, and kept constant at $220^{\circ} \mathrm{C}$ for $10 \mathrm{~min}$ and then programmed to $240^{\circ} \mathrm{C}$ at a rate of $1^{\circ} \mathrm{C} / \mathrm{min}$. Split ratio was adjusted at $40: 1$. The injector temperature was set at $250^{\circ} \mathrm{C}$. Mass spectra were recorded at $70 \mathrm{eV}$. Mass range was from $\mathrm{m} / \mathrm{z} 35$ to 450 . The sample was dissolved in $10 \% \mathrm{n}$-hexane and $1 \mu \mathrm{L}$ was injected.

\subsubsection{GC Analysis}

The GC analysis was carried out using an Agilent 7890B GC system. FID detector temperature was $300^{\circ} \mathrm{C}$. To obtain the same elution order with GC-MS, simultaneous auto-injection was done on a triplicate of the same column applying the same operational conditions. Relative percentage amounts of the separated compounds were calculated from FID chromatograms.

\subsection{Identification of Compounds}

Identification of the essential oil components was carried out by comparison of their relative retention times with those of authentic samples or by comparison of their linear retention index (LRI) 


\section{Volatile oil constituents of Crataegus species}

to series of n-alkanes. Computer matching against commercial (Wiley GC/MS Library, NIST Chemistry WebBook) [7,8] and in-house "Başer Library of Essential Oil Constituents" built up by genuine compounds and components of known oils, as well as MS literature data was used for the identification $[9,10]$.

\section{Results and Discussion}

The essential oils isolated by hydrodistillation from the inflorescences and unripe fruits of $C$. azarolus and C. pallasii were analyzed simultaneously by GC-FID and GC-MS. The chemical profiles of the essential oils, the percentage contents and linear retention indices of the components are shown in table 1. The components identified from the distilled oil of fresh $C$. azarolus were thirty-three forming $91.1 \%$ of the total oil composition and twenty-seven were identified from dried C. azarolus and thirty-one were determined from $C$. pallasii comprising $85.5 \%$ and $97.6 \%$ of the total oil composition, respectively. Oil yield of all samples was measured less than $0.01 \%$ on dry weight basis. The moisture content of $C$. azarolus was calculated as $65.6 \%$.

The major outstanding constituents and common to all samples of the essential oils of $C$. azarolus (fresh and dried) and $C$. pallasii were the alkanes namely; tricosane $(33.8 \%, 29.3 \%$ and $34.0 \%)$, pentacosane $(24.6 \%, 21.1 \%$ and $30.8 \%)$, heptacosane $(12.5 \%, 10.2 \%$ and $11.7 \%)$ and tetracosane $(6.0 \%, 5.6 \%$, and $5.7 \%)$, respectively. Docosane $(1.7 \%, 2.0 \%$, and $1.3 \%)$, was also present in all three samples. Carvacrol $(6.8 \%)$, carvacryl acetate $(0.3 \%)$, carvone (t) and thymol $(0.1 \%)$, were determined for the first time from $C$. pallasii essential oil. (E)- $\beta$-damascenone was determined only in dried C. azarolus; sesquiterpene compounds valencene, $\alpha$-selinene and $\beta$-selinene, $\delta$-cadinene, germacrene $\mathrm{D}$, selina-3,7(11)-diene, spathulenol, and $\delta$-cadinol were determined only in fresh $C$. azarolus sample. On the other hand $(2 E, 6 E)$-farnesol was characterized in both dried $C$. azarolus $(6.3 \%)$ and $C$. pallasii $(0.4 \%)$ samples.

Analysis of our readings documented an apparent difference between both samples of $C$. azarolus, most predominate the presence of hexacosane (1.3\%) in fresh C. azarolus and $(2 E, 6 E)$ farnesol (63\%) in dry C. azarolus samples. Eighteen compounds were common to both, this variation in chemical composition is suspected to be due to, mainly two reasons. Firstly, samples have been collected from different localities in Cyprus and secondly, the difference in sample conditions (fresh and dried). Reports on the essential oils of C. azarolus in different regions of the world also showed considerable qualitative and quantitative variations. This is in accordance with the fact that essential oil formation in the plants is highly dependent on climatic conditions, genetic background, biotic, and abiotic environmental factors, part of the plant distilled, stage of plant development as well as the extraction methods [11].

Comparison of our investigations with the published data regarding the essential oil of $C$. azarolus; Lakache and his colleagues reported sixty-one compounds from the essential oil of leaves and flowers of $C$. azarolus growing in Algeria by two extraction methods; hydrodistillation assisted by microwave heating (HD-MW) and hydrodistillation (HD). The main groups of detected volatiles were acids and esters (12 compounds) 27.5\% for HD-MW, 50.7\% for HD; alkanes and alkenes (17 components) comprised $40.8 \%$ for HD-MW, $29.5 \%$ for HD. It is obvious that the latter group of compounds obtained by using HD-MW method is quite similar to our results [12]. The Algerian $C$. azarolus aerial parts were also investigated by Boudjada et al., five volatile compounds were identified; 2,4-bis (1,1-dimethyl ethyl)-phenol, tridecanoic acid 12-methyl-methyl ester, pentadecanoic acid 14-methyl-methyl ester, 8-octadecanoic acid methyl ester, and isobutyl nonyl phthalate [13]. The water, methanolic and ethanolic extract of the fresh leaves of the Lebanese C. azarolus were examined by gas chromatography coupled with mass spectrometry. In total 11 compounds were determined in the water extract with the major compound pluchidiol (33.6\%). The methanolic extract revealed 8 compounds with the major compound $\alpha$-tocopherol-beta-d-mannoside (21.9\%) and in the ethanolic extract, 7 compounds were determined with the major compounds $\gamma$-tocopheryl methyl $(43.7 \%)$ and phytol isomer (20.5\%) [14]. 
Agiel et.al., Rec. Nat. Prod. (2019) 13:5 405-412

Table 1. Volatile oil composition of inflorescences and immature fruits of C. azarolus and C. pallasii

\begin{tabular}{|c|c|c|c|c|c|}
\hline LRI EXP & LRILIT $^{*}$ & Compound Name & A\% & B\% & $\mathrm{C} \%$ \\
\hline 1020 & $1025^{b}$ & $\alpha$-pinene & 0.9 & 0.3 & - \\
\hline 1190 & $1177^{b}$ & $\alpha$-terpinene & - & - & 0.1 \\
\hline 1213 & $1212^{\mathrm{c}}$ & Limonene & 1.9 & 0.5 & - \\
\hline 1259 & $1245^{b}$ & $\gamma$-terpinene & - & - & 0.7 \\
\hline 1288 & $1282^{c}$ & $p$-cymene & 0.4 & - & 0.3 \\
\hline 1408 & $1391^{b}$ & Nonanal & 0.2 & 0.2 & 0.1 \\
\hline 1514 & $1491^{b}$ & $\alpha$-copaene & 0.2 & - & - \\
\hline 1555 & $1543^{b}$ & Linalool & - & - & 0.4 \\
\hline 1613 & $1591^{b}$ & $\beta$-elemene & 0.1 & 0.2 & 0.2 \\
\hline 1622 & $1617^{a}$ & Undecanal & 0.1 & 0.3 & 0.2 \\
\hline 1620 & $1617^{\mathrm{a}}$ & Terpinen-4-ol & - & - & 0.3 \\
\hline 1624 & $1623^{a}$ & $\beta$-caryophyllene & 0.3 & 0.2 & 0.2 \\
\hline 1728 & $1719^{a}$ & Borneol & - & - & 0.2 \\
\hline 1744 & $1726^{a}$ & Germacrene D & 0.2 & - & - \\
\hline 1748 & $1741^{\mathrm{a}}$ & $\beta$-bisabolene & - & - & 0.3 \\
\hline 1758 & $1742^{\mathrm{d}}$ & $\beta$-selinene & 0.2 & - & - \\
\hline 1761 & $1744^{\mathrm{a}}$ & $\alpha$-selinene & 0.1 & - & - \\
\hline 1763 & $1760^{a}$ & $(E, E)$ - $\alpha$-farnesene & 0.3 & 0.4 & 0.4 \\
\hline 1770 & $1740^{\mathrm{a}}$ & Valencene & 0.5 & - & - \\
\hline 1770 & $1751^{a}$ & Carvone & - & - & $\mathrm{t}$ \\
\hline 1786 & $1755^{b}$ & $\delta$-cadinene & 0.2 & - & - \\
\hline 1817 & $1797^{\mathrm{a}}$ & Selina-3,7(11)-diene & 0.2 & - & - \\
\hline 1835 & $1830^{a}$ & Tridecanal & - & 0.2 & 0.1 \\
\hline 1854 & $1838^{a}$ & $(E)$ - $\beta$-damascenone & - & 0.1 & - \\
\hline 1875 & $1854^{b}$ & $(Z)$-geranyl acetone & - & 0.1 & - \\
\hline 1893 & $1880^{\mathrm{e}}$ & 2,2,4-trimethyl-3-carboxyisopropyl pentanoic acid isobutyl ester & - & 0.1 & - \\
\hline 1901 & $1890^{\mathrm{a}}$ & Carvacryl acetate & - & - & 0.3 \\
\hline 1941 & $1931^{\text {a }}$ & Phenylethyl alcohol & - & - & 0.1 \\
\hline 1973 & $1954^{\mathrm{a}}$ & $(E)-\beta$-Ionone & - & - & 0.1 \\
\hline 2033 & $2008^{a}$ & Caryophyllene oxide & 0.5 & - & - \\
\hline 2052 & $2053^{a}$ & $(E)$-nerolidol & 0.8 & 1.0 & - \\
\hline 2075 & $2055^{a}$ & Anisaldehyde & - & - & 0.1 \\
\hline 2100 & $2100^{a}$ & Eicosane & 1.9 & 3.8 & 1.6 \\
\hline 2110 & $2095^{a}$ & Hexyl benzoate & 0.1 & 0.3 & 0.1 \\
\hline 2138 & $2118^{a}$ & Hexahydrofarnesyl acetone & 0.4 & 0.2 & - \\
\hline 2159 & $2144^{\mathrm{a}}$ & Spathulenol & 0.2 & - & - \\
\hline 2163 & $2148^{a}$ & (Z)-3-hexenyl benzoate & 0.5 & 0.6 & 0.2 \\
\hline 2182 & $2170^{f}$ & (E)-2-hexenyl benzoate & 0.1 & 0.2 & 0.1 \\
\hline 2197 & $2191^{\mathrm{a}}$ & 3,4-dimethyl-5-pentylidine-2(5H)-furanone & - & $\mathrm{t}$ & - \\
\hline 2200 & $2200^{\mathrm{d}}$ & Docosane & 1.7 & 2.0 & 1.3 \\
\hline 2210 & $2198^{a}$ & Thymol & - & - & 0.1 \\
\hline 2228 & $2223^{a}$ & Methyl hexadecanoate & - & 0.3 & - \\
\hline 2230 & $2233^{\mathrm{a}}$ & $\delta$-cadinol & 0.2 & - & - \\
\hline 2242 & $2239^{a}$ & Carvacrol & - & - & 6.8 \\
\hline 2265 & $2278^{d}$ & Torilenol & 0.3 & - & - \\
\hline 2300 & $2300^{\mathrm{d}}$ & Tricosane & 33.8 & 29.3 & 34.0 \\
\hline 2332 & $2351^{a}$ & Eudesma-4(15),7-dien-1- $\beta$-ol & 0.2 & - & - \\
\hline 2370 & $2369^{a}$ & $(2 E, 6 E)$-farnesol & - & 6.3 & 0.4 \\
\hline 2402 & $2400^{\mathrm{d}}$ & Tetracosane & 6.0 & 5.6 & 5.7 \\
\hline 2416 & $2376^{a}$ & Manoyl oxide & 0.2 & 0.7 & - \\
\hline 2500 & $2500^{\mathrm{d}}$ & Pentacosane & 24.6 & 21.1 & 30.8 \\
\hline 2602 & $2600^{\mathrm{d}}$ & Hexacosane & 1.3 & - & 0.7 \\
\hline 2623 & $2613^{a}$ & Phytol & - & 1.6 & - \\
\hline \multirow[t]{2}{*}{2700} & $2700^{\mathrm{d}}$ & Heptacosane & 12.5 & 10.2 & 11.7 \\
\hline & & Total & 91.1 & 85.8 & 97.6 \\
\hline
\end{tabular}


Using solid phase microextraction (SPME) method, analysis of the volatile components of the leaf and flower of 7 Crataegus taxa collected from the Western Anatolia part of Turkey was conducted by Özderin et al. Forty volatile components from two samples of $C$. azarolus var. aronia essential oil were reported with the major components; benzaldehyde $(82.5 \%, 23.9 \%), 2$-hexenal $(21.7 \%, 2.5 \%)$, butyraldehyde $(15.2 \%, 4.4 \%)$ [15]. Due to the high popularity of the fruit jam of C. azarolus in Cyprus, Hadjimitsi and Zabetakis performed a study that involved the identification and quantification of volatile compounds from the commercial jam of the species purchased from a local producer in Cyprus. In that study, simultaneous distillation-extraction method was used and 44 components were identified by GC-MS. The major constituent identified was 2-furaldehyde (21.4\%) [16]. A study to evaluate the chemical profile of $C$. azarolus fruits in Northern Italy attempted an innovative approach, namely, a specific fingerprint, coupled to the multivariate data analysis (PCA), which was used to show the single bioactive class contribution to the total fruit phytocomplex. Five monoterpenes; phellandrene, sabinene, $\gamma$-terpinene, terpinolene and limonene constituting a total of $(15.4 \%)$ were characterized [17]. Hydrosol beverage of C. azarolus leaf and fruits that are used for the treatment of cardiovascular diseases in Persian nutrition culture and folk medicine was investigated by Azadeh $e t$ $a l$., and analyzed by GC-MS, to reveal the presence of hexadecanoic acid (7.7\%), $p$-xylene $(20.1 \%)$, thymol (28.7\%) and thymolethanoate (2.3\%) [18].

Other Crataegus species have also been investigated for their essential oil constituents. $C$. monogyna inflorescence essential oil was evaluated by Kowalski et al., and 65 compounds were identified, the major compounds were; tricosane (12\% - 17\%), heneicosane $(11 \%-16 \%)$, linalool $(6 \%$ $-11 \%)$, n-hexadecanoic acid (1\%-11\%), nonadecane (3\%-7\%), (E,E)- $\alpha$-farnesene $(1 \%-5 \%)$, caryophyllene oxide (1\%-4\%) and methyl eugenol (6\%) [23]. Whereas in early 1993, Robertson et al., also identified the major volatile compounds of C.monogyna flowers as alcohols, ketones and aldehydes; 3-methyl-1-butanol (23.2\%), benzaldehyde (16.1\%), 2-butanone (10.9\%), 3-methyl butanal (9.6\%), 4-methoxybenzaldehyde (9.2\%) 4-methoxy benzoic acid (9.6\%) and 3pyridinecarboxaldehyde (8.3\%) [24]. The essential oil of the flowers of C. jackii, C. robesoniana, and C. flabellata was reported by Kovaleva et al., 46 compounds were identified. The major compounds were alkanes, mainly; tricosane $(11.1 \%, 19.2 \%, 17.9 \%)$ which is in agreement with our results [25]. Özderin et al., identified fifty-three volatile components, from C. orientalis subsp. orientalis, collected from Muğla-Fethiye in Turkey. Major components were aldehydes; 2-hexenal (38.6\%), capronaldehyde $(6.8 \%)$ and from C. orientalis subsp. szovitsii major components were propyl methyl ketone (26.6\%), butyraldehyde (9.4\%) and 2-hexenal (6.6\%) [26]. Horvat and Chapman also investigated volatile oils from fruits of $C$. opaca, C. aestivalis and C. rufula from South Georgia. Twenty-four compounds were identified comprising mainly esters and aldehydes, constituting $70.4 \%$ of the volatiles [27]. The chemical characterization of $C$. oxyacantha essential oil from Algeria was determined by Chouitah and Meddah. Twenty-five compounds were detected, representing $97 \%$ of the total essential oil, eugenol (24.3\%), longifolenaldehyde (17.5\%), $\beta$-selinene (15.6\%) were the main components [28]. In a study by Nojima et al., to identify volatile compounds from hawthorn fruit (Crataegus spp.) that act as behavioral attractants for hawthorn-infesting Rhagoletis pomonella flies. Six volatiles were mentioned: ethyl acetate (94.3\%), 3-methylbutan1-ol (4\%), isoamyl acetate (1.5\%), 4,8-dimethyl-1,3(E),7-nonatriene $(0.1 \%)$, butyl hexanoate $(0.01 \%)$, and dihydro- $\beta$-ionone $(0.1 \%)$ [29].

\section{Conclusion}

To the best of our knowledge, this is the first report regarding the volatile oil analysis of inflorescences and unripe fruits of two Crataegus species, Crataegus azarolus growing in Cyprus and Crataegus pallasii growing in Libya. Fifty-four compounds were identified by GC and GC-MS analysis. Scientific studies document that alkanes are considered important substances in practical and clinical uses with huge potential in the nutraceutical and pharmaceutical industries [30] and in pest management programs [31]. Therefore, the alkanes concentration of C. azarolus and C. pallasii can be evaluated for these purposes.

Moreover, the presence of monoterpenes, sesquiterpenes, aldehydes, esters, ketones and the important constituent $(E)$ - $\beta$-damascenone which is regarded as a useful marker for characterisation of 


\section{Agiel et.al., Rec. Nat. Prod. (2019) 13:5 405-412}

the quality of rose oil and wine [32,33] that was isolated for the first time in minute amounts from Bulgarian rose oil [34] also suggests the use of C. azarolus and C. pallasii in food, cosmetics, and pharmaceutical industries to improve flavor and taste $[35,36,37]$. On the other hand, current literature documents the importance of flavonoids and oligomeric-proanthocyanidins in the treatment of cardiovascular disease by Crataegus species, it is noteworthy to investigate whether the volatile oil of Crataegus sp. would be responsible for other pharmacological properties of this genus e.g: anxiolytic, antiviral, antimicrobial, antioxidant, etc. $[1,38]$. Thus, further research is recommended to investigate the biological and economic importance of the essential oil of C. azarolus and C. pallasii.

\section{Acknowledgments}

The authors thank Near East University Research Projects (SAG-2017-01-017). The author Najat A. Agiel is thankful to the Higher Institute of the Libyan Education and the University of Tripoli- Libya for granting her the opportunity of Ph.D. scholarship at Near East University. Special thanks to MSc. Fatma El-theera, University of Benghazi, Faculty of Science, Botany Department for collecting Crataegus pallasii samples.

\section{Conflict of interest statement}

The authors have no conflict of interest to declare.

\section{Supporting Information}

Supporting information accompanies this paper on http://www.acgpubs.org/journal/records-ofnatural-products

\section{ORCID}

Najat Agiel: 0000-0003-4620-0019

Duygu Y. Hanoglu: 0000-0003-1345-4768

Azmi Hanoglu: 0000-000207586-9080

Kemal H. C. Baser : 0000-0003-2710-0231

Filiz Mericli : 0000-0002-4172-5417

\section{References}

[1] K. Dinesh, A. Vikrant, A. B. Zulfiqar, A. K. Nisar and N. P. Deo (2012). The genus Crataegus: chemical and pharmacological perspectives, Rev. Bras. Farmacogn. 22,1187-1200.

[2] M. Yanar, S. Ercisli, K. Yilmaz, H. Sahiner, T. Taskin, Y. Zengin, I. Akgul and F. Celik (2011). Morphological and chemical diversity among hawthorn (Crataegus spp.) genotypes from Turkey, Sci. Res. Essays. 6, 35-38.

[3] F. J. C. Holubarsch, S. W. Colucci and J. Eha (2017). Benefit-risk assessment of Crataegus extract WS 1442: An evidence-based review, Am. J. Cardiovasc. Drugs. 18, 25-36.

[4] J. Wang, X. Xiong, and B. Feng (2013). Effect of Crataegus usage in cardiovascular diseases prevention: An Evidence-Based Approach, Evid-Based Compl. Alt. Med.149393, 16 pages. doi: $10.1155 / 2013 / 149363$.

[5] A. J. Lund (2016). Methods for differentiation and phytochemical investigation of Crataegus by nuclear magnetic resonance spectroscopy, master thesis in Biochemistry and Molecular Biology, University of British Columbia, Canada.

[6] J. E. Edwards, P. N Brown, N. Talent, T.A. Dickinson and P. R. Shipley (2012). A review of the chemistry of the genus Crataegus, Phytochemistry. 79, 5-26.

[7] F. W. McLafferty and D. B. Stauffer (1989). The Wiley/NBS Registry of Mass Spectral Data, J Wiley and Sons: New York.

[8] P. J. Linstrom and W. G. Mallard, Eds., NIST Chemistry WebBook, NIST Standard Reference Database Number 69, National Institute of Standards and Technology, Gaithersburg MD, 20899, https://doi.org/10.18434/T4D303, (retrieved December 12, 2018). 


\section{Volatile oil constituents of Crataegus species}

[9] D. Joulain and W. A. Koenig (1998). The Atlas of Spectra Data of Sesquiterpene Hydrocarbons, EBVerlag, Hamburg.

[10] ESO 2000 (1999). The Complete Database of Essential Oils, Boelens Aroma Chemical Information Service, Netherlands.

[11] K. H. C. Baser and G. Buchbauer (2010). Handbook of Essential Oils: Science, Technology, and Applications. CRC Press: Boca Raton, Florida, United States.

[12] Z. Lakache, N. Tigrine-Kordjani, C. Tigrine, A. Kameli, and Y. B. Meklati (2014). Volatile constituents phenolic compounds, and antioxidant activity of Crataegus azarolus leaves and flowers growing in Algeria, Chem. Nat. Compd. 50, 986-988.

[13] A. Boudjada, A. Touil, H. Bendif, C. Bensouici and S. Rhouati (2018). Phytochemical constituents, phenolic contents, and antioxidant activity of Crataegus azarolus extracts, Asian J. Pharm. Clin. Res. 11, 133-137

[14] H. Kallassy, M. Fayyad-Kazan, R. Makki, Y. Yolla EL-Makhour, E. Hamade, H. Rammal, Y. D. Leger, V. Sol, H. Fayyad-Kazan, B. Liagre, B. Badran (2017). Chemical composition, antioxidant, anti-inflammatory, and antiproliferative activities of the plant Lebanese Crataegus azarolus L, Med. Sci. Monit. Basic. Res. 23, 270-284.

[15] S. Özderin, H. Fakir and E. Dönmez (2016). Chemical properties of hawthorn (Crataegus 1. spp.) taxa naturally distributed in western Anatolia part of Turkey, Prethodnopriopćenje 7, 369-376.

[16] E. Hadjimitsi and I. Zabetakis (2005). The aroma of jam prepared from fruits of mosphilla (Crataegus azarolus L.), Flavour Fragr. 20, 507-511.

[17] D. Donno, G. M. Mellano, Z. Prgomet, K. A. Cerutti, and L. G. Beccaro (2017). Phytochemical characterization and antioxidant activity evaluation of Mediterranean medlar fruit (Crataegus azarolus L.): Preliminary study of underutilized genetic resources as a potential source of a healthpromoting compound for food supplements, J. Food Nutr. Res. 56, 18-31.

[18] A. Hamedi, M. M. Seyed, S. Amirhossein, E. Hamed and M. Mahmoodreza (2017). An Overview on indications and chemical composition of aromatic waters (Hydrosols) as functional beverages in Persian nutrition culture and folk medicine for hyperlipidemia and cardiovascular conditions, J. EvidBased Compl. Alt. Med. 22, 544-561.

19] V. I. Babushok, P. J. Linstrom and I. G. Zenkevich (2011). Retention indices for frequently reported compounds of plant essential oils, J. Phys. Chem. Ref. Data. 40, 043-101.

[20] http://www.pherobase.com/database/kovats/kovats- detailsulcatone.php.(Accessed date:20.1.2019).

[21] B. Demirci, M. Toyota, F. Demirci, M. Y. Dadandi and K. H. C. Baser (2009). Anticandidal pimaradiene diterpene from Phlomis essential oils, C. R. Chimie. 12, 612-621.

[22] M. Tekin, E. Martin, T. Ozek, G. Yilmaz and K. H. C. Baser (2018). Essential oil characterization of Cousinia sivasica Hub.-Mor. (Asteraceae), BioDiCon. 651-0217.

[23] R. Kowalski, G. Kowalska, K. Kalwa and M. Sujka (2018). Essential oil composition of hawthorn Crataegus monogyna inflorescence, Chem. Nat. Compd. 54, 995-997.

[24] G. W. Robertson, D. W. Griffiths, J. A. T. Woodford, A. N. E. Birch, J. A. Picket and L. J. Wadhams (1993). A comparison of the flower volatiles from hawthorn and four raspberry cultivars, Phytochemistry. 33, 1047-1053.

[25] A. M. Kovaleva, N. F. Goncharov and A. N. Komissarenko (2009). GC/MS study of essential oil components from flowers of Crataegus jackii, C. robesoniana, and C. flabellata, Chem. Nat. Compd. 45, 582-584.

[26] S. Özderin, H. Faki and E. Dönmez (2015). Determination to volatile components of some Crataegus orientalis Pall. Ex M.Bieb. taxa in Muğla-Fethiye Province, J. Nat. Appl. Sci. 19, 120-123.

[27] R. J. Horvat and G. W. Chapman (1991). Identification of volatile oils from ripe fruit Mayhaw fruit (Crataegus opaca, C.aestivalis, and C.rufula), J. Food Quality. 14, 307-312.

[28] O. Chouitah and B. Meddah (2018). Essential oil from the leaves of Crataegus oxyacantha: Chemical composition and antimicrobial activity, BFIJ. 10, 52-55.

[29] S. Nojima, C. Linn, B. Morris, A. Zhang and W. Roelofs (2003). Identification of host fruit volatiles from Hawthorn (Crataegus spp.) attractive to hawthorn-origin Rhagoletis pomonella flies, J. Chem. Ecology. 29, 319-334.

[30] S. K. Kim and F. Karadeniz (2012). Biological importance and applications of squalene and squalane, Adv. Food Nutr. Res. 65, 223-233.

[31] N. Sarkar and A. Barik (2014). Alkanes from bitter gourd as allelochemicals in olfactory responses of Epilachna dodecastigma (Wied.), Allelopat. J. 33, 43-52.

[32] I. Zuobing, L. Jing, N. Yunwei, W. Pinpin, W. Ruolin and S. Xiaoxin (2019). Olfactory impact of esters on rose essential oil floral alcohol aroma expression in model solution, Food Res. Int. 116, 211222. 
[33] S.Erbaş and H. Baydar (2016). Variation in scent compounds of oil-bearing rose (Rosa damascena Mill.) produced by headspace solid phase microextraction, hydrodistillation and solvent extraction Rec.Nat.Prod.. 10(5), 555-564.

[34] E. Demole, P. Enggist, U. Säuberli, M. Stoll and E. S. Kováts (1970). Structure et synthèse de la damascénone (triméthyl-2,6,6-trans-crotonoyl-1-cyclohexadiène-1,3) constituent odorant de l'essence de rose bulgare (Rosa damascena Mill) Helvetica Chim. Acta. 53, 541-551.

[35] A. Waleed, E. I. Sharaf, O. A. Khamis, H. A. M Hinawi, Y. Jiahao, A. Mohammed, R. Husnain and Z. Lianfu (2017). Volatile flavor compounds of peel and pulp from Doum (Hyphaene thebaica L.) Fruit, Am.J. Food Sci. Nutr. Res. 4, 165-169.

[36] S. A. G. A. Amanda, C. M. Alessandra, H. H. A. Pedro and O. Debora (2017). A review on enzymatic synthesis of aromatic esters used as flavor ingredients for food, cosmetics and pharmaceuticals industries, Trends Food Sci. Technol. 69, 95 -105.

[37] N. Yunwei, Y. Zhengmin, X. Qing, X. Zuobing, M. Ning and Z. Jiancai (2017). Characterization of the key aroma compounds in different light aroma type Chinese liquors by GC-olfactometry, GCFPD, quantitative measurements and aroma recombination, Food Chem. 233, 204-215.

[38] V. Schulz, R. Hänsel, M. Blumenthal and V. E. Tyler (2004). Rational Phytotherapy, A Reference Guide for Physicians and Pharmacists, Springer Verlag, Berlin, Heidelber.

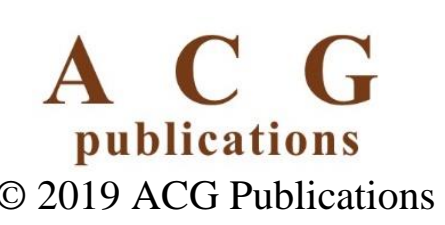

